\title{
The use of unstented homograft valves for aortic valve reoperations
}

\author{
Review of a twenty-three-year experience
}

Unstented homograft valves offer several theoretical advantages when used for patients who have had previous operations on the aortic valve. Between January 1970 and February 1993, 177 patients received unstented homograft valves after previous aortic valve operations. One hundred thirty-four patients had previous aortic valve replacement in the form of homografts (101 patients), mechanical prostheses ( 24 patients), and bioprostheses ( 9 patients), and 43 had previous valve repair. The indication for reoperation was deterioration of a noninfected valve (124 patients), infective endocarditis (40 patients), and failure of a noninfected mechanical valve (12 patients). Fresh homograft valves were implanted in 60 patients, homografts preserved in antibiotics were used in 111 patients, and 6 patients received cryopreserved valves. Aortic valve and root replacement was performed in 60 patients, and in 117 the homograft was inserted freehand in the subcoronary position. The early mortality was $5.1 \%$. The actuarial survival at 10 years was $71 \%$. Multivariate analysis demonstrated that patients with previous homograft replacement have a better long-term survival than patients who had previous mechanical valves $(p=0.017)$. The freedom from valve-related death and reoperation was $70 \%$ at 10 years. Fresh homografts faired better than antibiotic-sterilized homografts $(p=0.007)$. None of the patients had recurrence of endocarditis at 6 months, although 1 patient died of uncontrolled infection despite valve replacement. The freedom from recurrent endocarditis was $88 \%$ at 10 years. We conclude that unstented aortic homografts provide good early and long-term results for aortic valve reoperations, particularly in patients with previous homograft replacement. Recurrent endocarditis is uncommon even in patients operated on for prosthetic valve infections. (J THORAC Cardovasc SuRg 1994;107:152-61)

Mario Albertucci, MDa (by invitation), Kit Wong, FRCS ${ }^{\text {a }}$ (by invitation), Mario Petrou, BSc, MB, BS (by invitation), Andrew Mitchell, FRCP ${ }^{\mathrm{b}}$ (by invitation), Jane Somerville, MD, FRCP (by invitation), Stergios Theodoropoulos, $\mathrm{MD}^{\mathrm{a}}$ (by invitation),

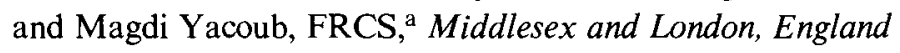

$\mathrm{R}$ problems because of a variety of factors including

From the Academic Department of Surgery, Harefield Hospital and the Royal Brompton, National Heart and Lung Hospital, ${ }^{\text {a }}$ and the Department of Cardiology, Harefield Hospital, Middlesex, ${ }^{b}$ and the Royal Brompton, National Heart and Lung Hospital, London, ${ }^{c}$ England.

Read at the Seventy-third Annual Meeting of The American Association for Thoracic Surgery, Chicago, Ill., April 25-28, 1993.

Address for reprints: Magdi Yacoub, FRCS, Academic Department of Surgery, Royal Brompton, National Heart and Lung Hospital, Sydney St., London SW3, England.

Copyright $₫ 1994$ by Mosby-Year Book, Inc.

$0022-5223 / 94 \$ 1.00+.10 \quad \mathbf{1 2} / \mathbf{6} / \mathbf{5 0 8 5 8}$ advanced age, decreased myocardial function, and technical difficulties related to scarring and distortion of the aortic anulus and root. Unstented homografts offer many theoretical advantages, but their use is technically more demanding and their exact value and long-term performance for this specific group of patients remain to be defined.

This study reviews our experience with unstented homografts used for reoperations on the aortic valve. Their performance is evaluated and the determinants of early and long-term results are defined.

\section{Patients}

From January 1970 to February 1993, 177 patients had aortic valve reoperations at two hospitals (Harefield Hospital, 


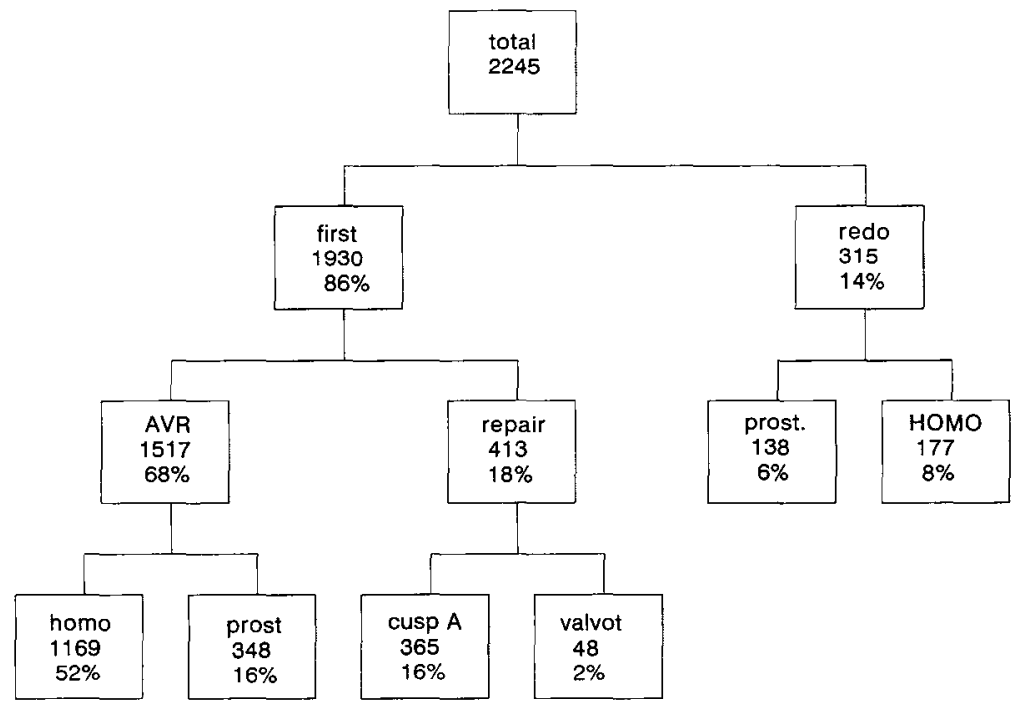

Fig. 1. Overall experience with aortic valve operations at Harefield Hospital and Royal Brompton and National Heart and Lung Hospital, 1970 to February 1993.

Table I. Type of valve used at the first operation and time interval between the first and second operations

\begin{tabular}{lccc}
\hline $\begin{array}{c}\text { Type of } \\
\text { first } \\
\text { operation }\end{array}$ & $\begin{array}{c}\text { No. of } \\
\text { patients }\end{array}$ & $\begin{array}{c}\text { Interval } \\
(y r)\end{array}$ & $S D$ \\
\hline Homograft & 101 & 9.48 & 5.06 \\
Valvotomy & 22 & 9.85 & 6.67 \\
Repair & 21 & 8.41 & 5.23 \\
Mechanical valve & 24 & 3.96 & 4.89 \\
Bioprosthetic valve & 9 & 5.78 & 4.02 \\
Total & 177 & 8.45 & 5.56 \\
\hline
\end{tabular}

Middlesex: 124 patients; Royal Brompton, National Heart and Lung Hospital, London: 53 patients) by the same surgeon (M.Y.). These patients comprised $8 \%$ of our overall experience with aortic valve operations (Fig. 1). There were 131 male and 46 female patients with a mean age of 45 years (range 2 to 77 years). The indication for the first operation was aortic stenosis (transvalvular gradient $>30 \mathrm{~mm} \mathrm{Hg}$ ) in 108 patients, aortic regurgitation in 42 patients, and infective endocarditis in 27 patients. One hundred thirty-four patients had previous aortic valve replacements in the form of homografts (101), mechanical prostheses (24), and bioprostheses (9). Forty-three patients had aortic valve repair (valvotomy in 22 and cusp augmentation in 21). The indications for reoperation were infection in 40 patients, noninfected tissue valve failure in 124 , and mechanical valve failure in 12 patients. Tissue valve failures included mainly regurgitation for the homografts and calcification with stenosis for bioprostheses. Calcification and stenosis were also predominant in the patients with cusp augmentation and valvotomy. Mechanical valve failures included noninfective paravalvular leaks ( 8 patients), hemolysis ( 2 patients), repeated embolic episodes ( 1 patient), and structural deterioration (ball
Table II. Preoperative NYHA classification

\begin{tabular}{lcc}
\hline Class & No. of patients & $\%$ \\
\hline I & 10 & 5.7 \\
II & 89 & 50.3 \\
III & 70 & 39.5 \\
IV & 8 & 4.5 \\
Total & $\mathbb{1 7 7}$ & $\mathbb{1 0 0 . 0}$ \\
\hline
\end{tabular}

variance, 1 patient). Of the 40 patients with endocarditis requiring valve replacement, 25 had a previous homograft, 12 had mechanical valves, 2 had bioprosthetic valves, and 1 had a repair. Half of those with mechanical valves who required reoperation ( 12 of 24 patients) had endocarditis. The mean interval between the first and the second operation was 8.5 years $\left(\mathrm{SD}^{*} \pm 5.53\right)$ and for the various subgroups is shown in Table I. Nineteen patients had two or more previous aortic valve operations.

Preoperative functional classification and left ventricular function. The preoperative New York Heart Association (NYHA) classification is shown in Table II. The left ventricular function was estimated in all patients by left ventriculography and more recently by echocardiography and judged to be good in 109 patients, moderately impaired in 62, and poor in 6 .

Technique of operation. Myocardial preservation was by hypothermic perfusion at $32^{\circ} \mathrm{C}$ and continuous coronary perfusion, particularly in patients with impaired left ventricular function. Crystalloid cardioplegia (St. Thomas' Hospital No. 1) was used in root replacement for the period of reimplantation of the coronary arteries only. An apical vent was used in every case.

Aortic valve and root replacement was performed in 60 patients, and in 117 patients the homograft was inserted free-

*SD $=$ Standard deviation. 
Table III. Concomitant procedures $(n=177)$

\begin{tabular}{lcl}
\multicolumn{1}{c}{ Procedure } & $\begin{array}{c}\text { No. of } \\
\text { patients }\end{array}$ & $\%$ \\
\hline Mitral replacement & 14 & 7.9 \\
CABG & 10 & 5.7 \\
Mitral repair & 2 & 1.1 \\
Myotomy/myectomy & 2 & 1.1 \\
Replacement of & 2 & 1.1 \\
$\quad$ ascending aorta & & \\
Tricuspid repair & 1 & 0.6 \\
ASD closure & $\frac{1}{32}$ & 0.6 \\
Total & & 18.1
\end{tabular}

$C A B G$, Coronary artery bypass grafting; $A S D$, atrial septal defect.

Table IV. Antibiotic solutions used for homograft preservation

\begin{tabular}{cc}
\hline \multicolumn{1}{c}{ Solution } & Dose \\
\hline Harefield (/100 ml Hartmann's, $1970-1993)$ \\
Carbenicillin & $1 \mathrm{gm}$ \\
Cefotaxime & $1 \mathrm{gm}$ \\
Gentamicin & $80 \mathrm{mg}$ \\
Polymyxin B & $500,000 \mathrm{IU}$ \\
Amphotericin B & $25 \mathrm{mg}$ \\
DANYNM (/100 ml T 199, 1970-1991, Brompton) \\
Carbenicillin & $1 \mathrm{gm}$ \\
Cephaloridine & $40 \mathrm{mg}$ \\
Neomycin & $100 \mathrm{mg}$ \\
Polymyxin B & $500,000 \mathrm{IU}$ \\
Nystatin & $50 \mathrm{mg}$ \\
Gaya 3 (/100 ml T 199, 1970-1993, Brompton) \\
Trimethoprim & $10 \mathrm{mg}$ \\
Ciprofloxacin & $20 \mathrm{mg}$ \\
Vancomycin & $50 \mathrm{mg}$ \\
Polymyxin B & $500,000 \mathrm{IU}$ \\
Amphotericin B & $10 \mathrm{mg}$ \\
Rifampicin & $60 \mathrm{mg}$
\end{tabular}

$D A N Y N M$, Dilute antibiotic nystatin nutrient medium.

hand in the subcoronary position. The aortic valve was exposed through a curved aortotomy starting in the midline anteriorly and extending into the middle of the noncoronary cusp. This allowed excellent exposure of the valve and possible enlargement of the root by extending the incision across the anulus into the subaortic curtain for 2 to $3 \mathrm{~mm}$. The indication for root replacement was determined after exposure of the aortic valve and based on the size of the root, its distortion, and the need to exteriorize abscess cavities in the case of infective endocarditis. The techniques used for freehand and root replacement with homografts have been described earlier., 2

In cases of infective endocarditis the aim was to exteriorize the abscess cavities and to excise the infected tissue down to healthy noninfected tissue. When débridement extended below the level of the anulus, the homograft was then sutured to the noninfected myocardium of the left ventricular outflow tract, with care taken to avoid the area of the atrioventricular bundle.

Seventeen patients $(9.6 \%)$ required emergency operations
Table V. Causes of early (30-day) mortality $(n=177)$

\begin{tabular}{lcc}
\multicolumn{1}{c}{ Cause } & $\begin{array}{c}\text { No. of } \\
\text { patients }\end{array}$ & $\%$ \\
\hline Left ventricular failure & 4 & 2.2 \\
Arrhythmias & 2 & 1.1 \\
Bleeding & 1 & 0.6 \\
Multiorgan failure & 1 & 0.6 \\
Respiratory failure & $\frac{1}{9}$ & 0.6 \\
Total & 5.1 \\
\hline
\end{tabular}

and 32 patients had concomitant procedures as presented in Table III.

Homograft details. Fresh homograft valves were harvested at the time of heart transplantation from the recepient heart under sterile conditions and kept in nutrient solution (Medium 199 with Earle's salts, ICN Biomedicals, High Wycombe, Bucks., England) in 60 patients (mean time from harvest to implantation of 3.8 days, range 0.5 to 39 days).$^{3}$ In 111 patients the homograft was sterilized in antibiotic solution after harvest and stored at $4^{\circ} \mathrm{C}$ (mean time from harvest to implantation 9.8 days, range 1 to 54 days). Six patients received cryopreserved homografts. Table IV details the types of antibiotic solutions used.

Follow-up. Complete outpatient follow-up at 1-year or 2-year intervals was carried out in $157(88.7 \%)$ patients and comprised assessment of functional status, physical examination, review of cardiovascular medications, and echocardiography. Twenty patients lived abroad and follow-up information on them was incomplete after 6 months to 1 year. The definition and mode of reporting morbidity and mortality were in accordance with the guidelines recommended by the Ad Hoc Liason Committee for Standardizing Definitions of Prosthetic Heart Valve Morbidity. ${ }^{3}$

Statistical methods. The $\chi^{2}$ test was used to compare frequencies of the different variables and a $p$ value of less than 0.05 was considered significant. The probability of survival, freedom from valve-related death and reoperation, and freedom from endocarditis were calculated by the Kaplan-Meier method. $^{4}$

Logistic regression was used to analyze factors affecting early mortality. According to this model, $\mathrm{P}$, the probability of early death, is related to the covariates, $\mathrm{x}_{1}, \mathrm{x}_{2}, \ldots, \mathrm{x}_{\mathrm{k}}$ as follows:

$$
\log (\mathrm{P} / 1-\mathrm{P})=\beta_{0}+\beta_{1} \mathrm{x}_{1}+\beta_{1} \mathrm{x}_{2}+\ldots \beta_{\mathrm{k}} \mathrm{x}_{\mathrm{k}}
$$

where $\beta_{1}, \beta_{2}, \ldots, \beta_{\mathrm{k}}$ are the coefficients measuring the degree of influence of the covariates. Notice that if $\beta_{\mathrm{i}}$ is positive then the increasing value of $x_{i}$ leads to increasing probability of early death. Likelihood-based methods were used in fitting and testing the models. The statistical computer package BMDP (1990) was used to fit the models. ${ }^{5}$

The Cox proportional hazard model ${ }^{6}$ was used to analyze the time of follow-up after the reoperation and the time until death or second reoperation among those patients who did not die early after the operation. According to the Cox model, the hazard function at time $t$ for a patient with covariates $x_{1}, x_{2}, \ldots, x_{k}$ is given by the following equation:

$$
\mathrm{h}(\mathrm{t} ; \mathrm{x})=\mathrm{h}_{0}(\mathrm{t}) \exp \left\{\beta_{1} \mathrm{x}_{1}+\beta_{2} \mathrm{x}_{2}+\ldots+\beta_{\mathrm{k}} \mathrm{x}_{\mathrm{k}}\right\}
$$

where $h_{0}(t)$ is the baseline hazard and the parameters $\beta_{1}, \ldots$, $\beta_{\mathrm{k}}$ are coefficients measuring the degree of influence of the 


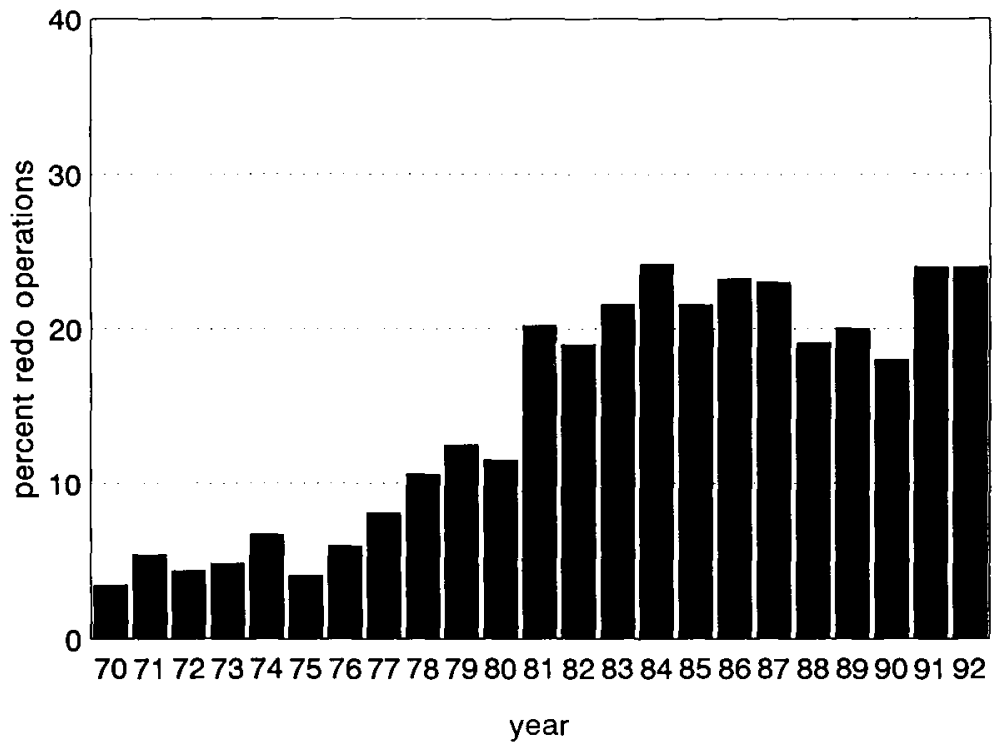

Fig. 2. Aortic reoperations as percentage of total aortic operations performed over 23-year period.

Table VI. Logistic regression analysis for early (30-day) mortality

\begin{tabular}{lcc}
\multicolumn{1}{c}{ Covariate } & \multicolumn{1}{c}{ Coefficient } & p Value \\
\hline NYHA class & 2.445 (SE 1.17) & 0.037 \\
Left ventricular function & 1.962 (SE 1.16) & 0.091 \\
Year of operation & $-0.1174($ SE 0.0567) & 0.038 \\
\hline$K=-1.796$ (SE 0.73). & &
\end{tabular}

covariates of the hazard function. The hazard is a measure of the rate at which death occurs, so that a positive value of $\beta_{i}$ indicates that the increasing value of the covariate $x_{i}$ is associated with decreased survival time. Likelihood-based methods were used in fitting and testing models. ${ }^{5}$ Qualitative covariates such as "cause of failure of the first valve" were fitted by means of indicator variables. In the case of quantitative covariates such as "time between operation" a linear relationship was initially assumed. In cases in which this was significant, the possibility of curvature was explored by adding a quadratic term. Investigations were also made into the possibility of interaction between covariates. The standard errors for the estimated survival probability were obtained by means of a boot-strapping method. ${ }^{7}$

\section{Results}

Early mortality and morbidity. The early (30-day) mortality for all the patients was $5.1 \%$ (9 of $177,90 \%$ confidence limits [CL] 3.5\% to 7.5\%), the causes of which are listed in Table V. Logistic regression was used to analyze factors affecting early mortality. Possible covariates included age, gender, diagnosis at the first operation, multiple previous aortic operations, type of first operation, indication for the second operation, reoperation interval, date of the second operation, NYHA class, left ventric-
Table VII. Nonfatal postoperative complications $(n=177)$

\begin{tabular}{lcc}
\hline \multicolumn{1}{c}{ Complication } & $\begin{array}{c}\text { No. of } \\
\text { patients }\end{array}$ & $\%$ \\
\hline Arrhythmias* & 10 & 6.9 \\
Respiratory. & 6 & 3.4 \\
Low cardiac output & 5 & 2.8 \\
Bleeding & 4 & 2.2 \\
Neurologic & 4 & 2.2 \\
Complete heart block & 3 & 1.7 \\
Acute renal failure & 2 & 1.1 \\
Miscellaneous & 3 & 1.7 \\
Total & $\frac{3}{37}$ & 22.0 \\
\hline
\end{tabular}

*Excluding atrial fibrillation.

ular function, urgency of operation (elective or emergency), type of operation (freehand or root), and concomitant procedures. NYHA class IV and poor left ventricular function were incremental risk factors for early deaths ( $p=0.037$ and 0.091 , respectively). Early (30-day) mortality significantly decreased in the more recent era ( $p=0.038$, Fig. 2). Table VI shows the results of the logistic regression analysis. According to this model, the predicted early mortality for a patient with NYHA class II, good to moderate left ventricular function requiring replacement of a homograft valve in 1993 is $1.4 \%(90 \%$ CL $0.3 \%$ to $4.1 \%$ ). In contrast, a matched patient but with more advanced symptoms (NYHA class IV) has a prediced early mortality of $11.4 \%$ (90\% CL $2.5 \%$ to $39.3 \%$ ).

Thirty-seven patients had significant but nonfatal postoperative complications, as outlined in Table VII. 


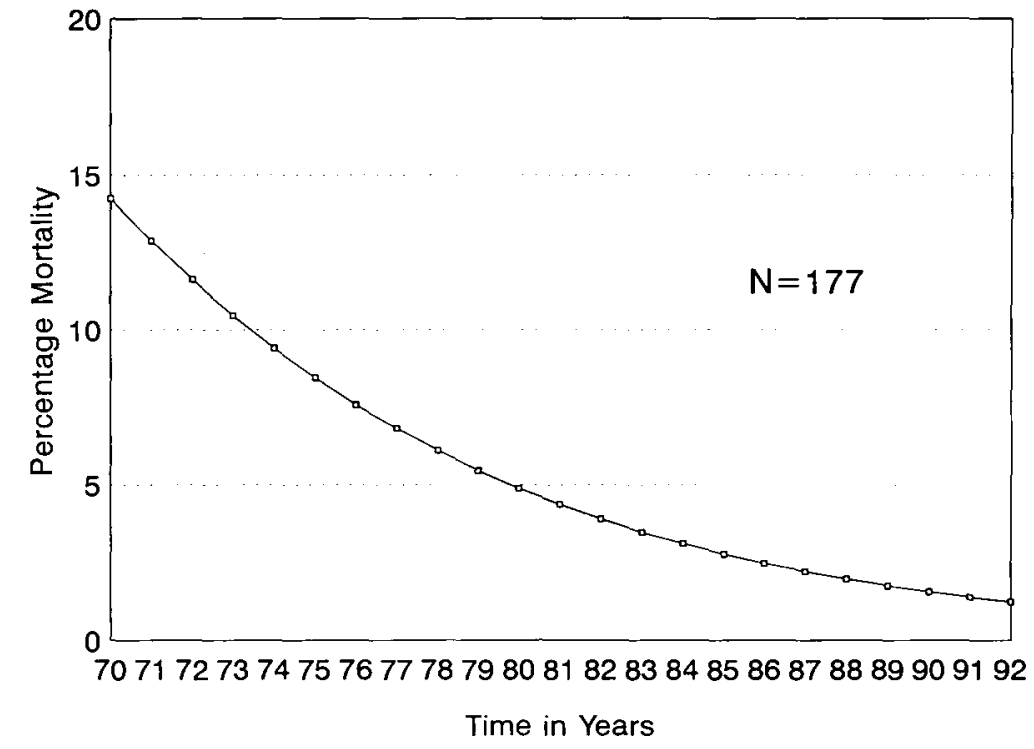

Fig. 3. Incidence of early death by year of operation as estimated by logistic regression model.

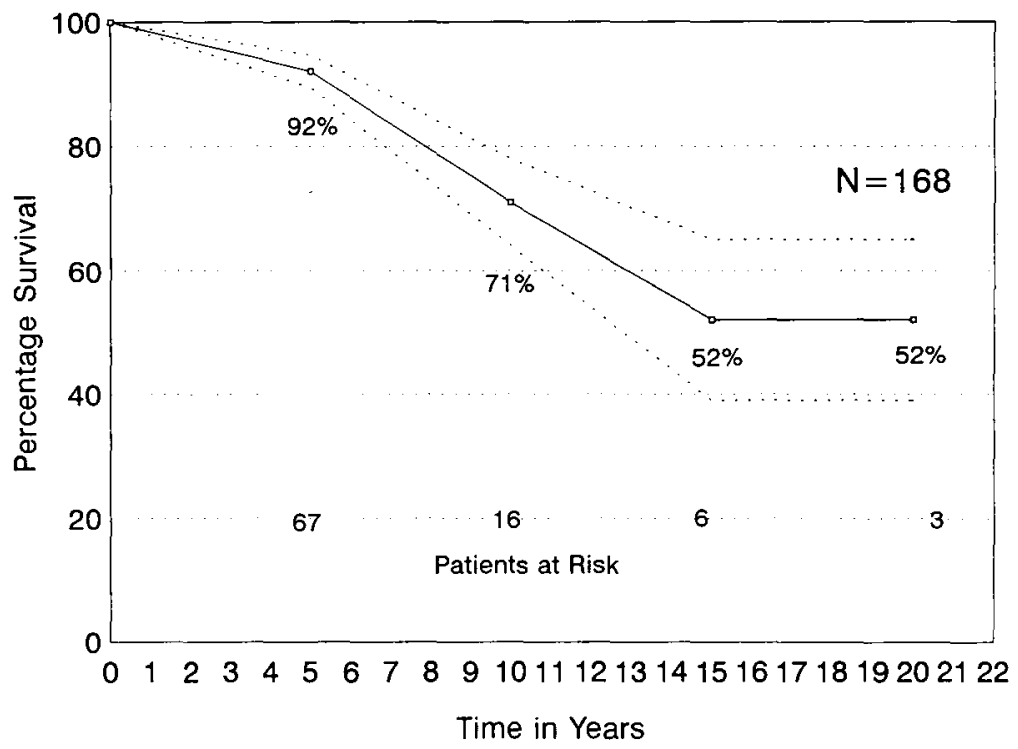

Fig. 4. Kaplan-Meier estimate of probability of survival after reoperations with unstented homografts. Early mortality is excluded.

Three patients required support with intraaortic balloon counterpulsation and were successfully weaned. Four patients required reexploration for excessive bleeding. Complete heart block necessitating permanent pacemaker implantation developed in three patients who had infective endocarditis with abscess cavities involving the intraventricular septum. The neurologic events occurring in three of four patients were transient and resolved before hospital discharge.
The mean length of stay in the intensive care unit was 2 days (range 8 hours to 35 days). The mean length of hospital stay was 14 days (range 6 to 90 days).

Late mortality. The actuarial survival curve is shown in Fig 4. The interval survivals at 5, 10, and 15 years were 92\% $\left(\mathrm{SE}^{*} \pm 2.6\right), 71 \%(\mathrm{SE} \pm 7.0)$, and $52 \%(\mathrm{SE} \pm$ 13.4), respectively. Table VIII outlines the causes of late

* $\mathrm{SE}=$ Standard error. 


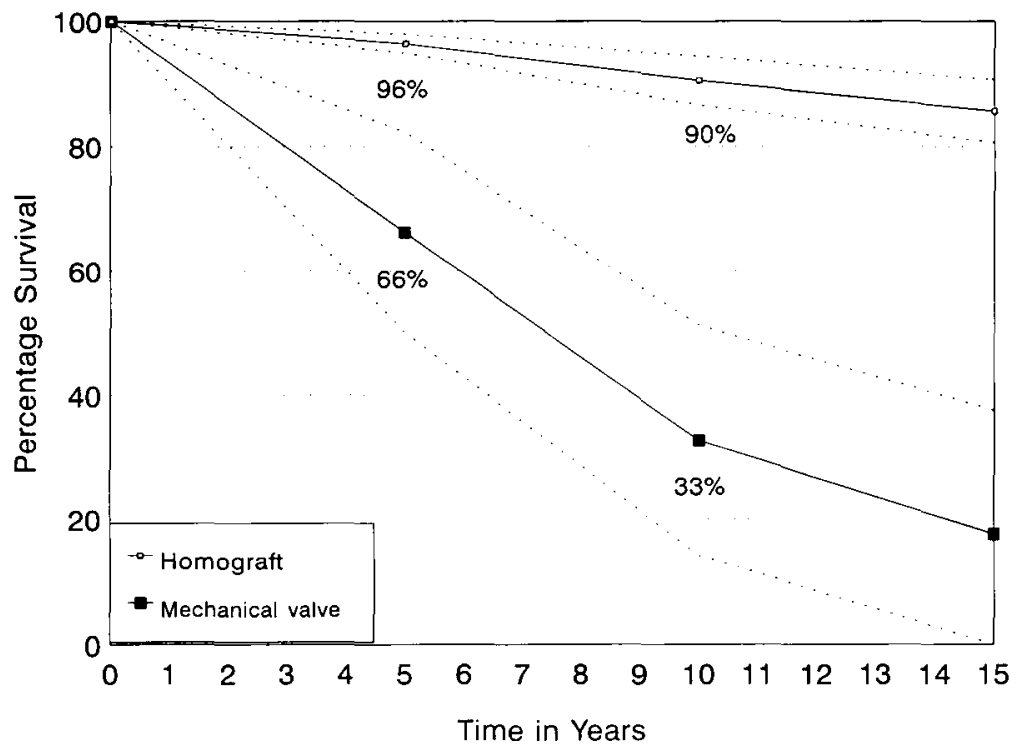

Fig. 5. Probability of survival for patients who had homografts implanted at first operation versus patients who had mechanical valve implanted at first operation. Predicted survival based on Cox proportional hazard model.

Table VIII. Causes of late death and time of occurrence $(n=168)$

\begin{tabular}{lccccc}
\hline \multicolumn{1}{c}{ Cause } & & & \multicolumn{2}{c}{ Time $(y r)$} \\
\cline { 5 - 5 } No. of patients & $\%$ & 4.8 & & Range & Mean \\
\hline Sudden death & 8 & 3.6 & $1-13$ & 4.75 \\
Congestive heart failure & 6 & 1.2 & $0.2-1$ & 4.91 \\
Infective endocarditis & 2 & 1.2 & $8-14$ & \\
Cancer & 2 & 1.2 & $7-10$ & \\
Unknown & 2 & 12.0 & $0.2-14$ & 5.38 \\
Total & 20 & & & \\
\hline
\end{tabular}

death. Sudden death was not related to a preoperative diagnosis of aortic stenosis versus regurgitation $(p=0.6)$. Cardiac failure resulted from aortic regurgitation in one patient and mitral regurgitation with a normally functioning aortic homograft in one other patient. In the remaining four patients the cause of the cardiac failure, although not confirmed, was attributed to aortic homograft failure for the purpose of the analysis. The cause of death was confirmed at postmortem examination in $45 \%$ of cases and reported by the referring physician in the remainder. The Cox proportional hazard model was used to analyze the factors influencing long-term survival. The possible covariates included all those used in the analysis of early mortality, plus the type of homograft used, the presence of postoperative complications, functional status (NYHA), and evidence of aortic valve dysfunction by physical examination and echocardiography at the latest follow-up visit. The patients who had previous mechanical valve failure were at increased risk of late death $(p=0.017)$. The hazard rate decreases as the interval between the first and second operation increases $(p=0.005)$. The results of the multivariate analysis are shown in Table IX. According to this model a 60 -year-old patient with NYHA class II symptoms who requires replacement of a homograft aortic valve implanted 12 years before has a $96 \%(\mathrm{SE} \pm 1.5 \%)$ probability of being alive at 5 years and a $90 \%(\mathrm{SE} \pm 3.9 \%$ ) probability at 10 years. In contrast, a 60-year-old patient with NYHA class II symptoms who requires replacement of a mechanical aortic valve after 4 years has a $66 \%$ (SE $\pm 16.1 \%$ ) probability of being alive at 5 years and a 33\% (SE $\pm 18.5 \%$ ) probability at 10 years (Fig. 5).

Homograft performance. At a median follow-up period of 6 years the NYHA class was I in 107 patients, II in 50, and III in 11 . One hundred patients were not receiving any cardiac medication (56\%). There were no cases of early or late paravalvular leaks. One hundred twenty-seven patients had no evidence of aortic regurgi- 
Table IX. Multivariate analysis (Cox model) for factors affecting long-term survival; type of first valve compares mechanical and bioprosthetic valves with homografts and valve repairs

\begin{tabular}{lcc}
\multicolumn{1}{c}{ Covariate } & Coefficient & $p$ Value \\
\hline Reoperation interval & -0.352 (SE 1.26) & 0.005 \\
Type of first valve & 1.27 (SE 0.54) & 0.017 \\
\hline
\end{tabular}

Table X. Multivariate analysis (Cox model) for factors affecting late valve-related death and reoperations; homograft type compares fresh with antibiotic-preserved homografts

\begin{tabular}{lcc}
\hline \multicolumn{1}{c}{ Covariate } & \multicolumn{1}{c}{ Coefficient } & $p$ Value \\
\hline Year of reoperation & 0.634 (SE 0.265) & 0.017 \\
Reoperation interval & -0.348 (SE 0.187) & 0.063 \\
Homograft type & -3.40 (SE 1.27) & 0.007 \\
\hline
\end{tabular}

tation by physical examination or echocardiography. Aortic regurgitation was mild in 24 patients, moderate in 14 , and severe in 3 . The latter required an elective second reoperation and, overall, 5 patients required second reoperations at $8,10,11,13$, and 14 years, respectively, without early mortality. The actuarial curve for freedom from valve-related death and reoperation is shown in Fig. 5. The interval freedoms at 5, 10, and 15 years were $94 \%$ $(\mathrm{SE} \pm 2.4 \%), 70 \%(\mathrm{SE} \pm 4.5 \%)$, and $45 \%$ (SE \pm $12.8 \%$ ), respectively. Multivariate analysis was performed and included the same variables used for the late mortality analysis and the time between harvesting and implantation of the homograft and the method of homograft preservation. The results of multivariate analysis are shown in Table $X$. The time interval between the first and the second operation had a direct relation with the homograft performance: the longer the interval the better the implanted homograft performed $(p=0.063$ ). In addition, operations performed in more recent years were associated with better homograft performance $(p=0.017)$, as were fresh homografts versus antiobioticpreserved homografts $(p=0.007)$.

No episodes of nonseptic thromboembolism occurred in any of the patients.

Infective endocarditis. Of the 40 patients with infective endocarditis requiring aortic valve replacement, 21 had active infection and 13 required emergency operation. The preoperative NYHA class was III or IV in 24 patients $(60 \%)$. Aortic valve and root replacement was necessary in 15 patients (37.5\%). The type of valve affected by endocarditis is shown in Table XI, and the organisms responsible for the infection are shown in Table
Table XI. Type of valve in patients with infective endocarditis

\begin{tabular}{lcc}
\hline \multicolumn{1}{c}{ Type of valve } & No. of patients & $\%$ \\
\hline Homograft & 25 & 62.5 \\
Mechanical valves & 12 & 30 \\
Bioprosthetic valves & 2 & 5 \\
Repair & $\frac{1}{40}$ & $\frac{2.5}{100.0}$ \\
Total & \\
\hline
\end{tabular}

Table XII. Organisms responsible for infective endocarditis

\begin{tabular}{lcc}
\hline \multicolumn{1}{c}{ Organism } & No. of patients & $\%$ \\
\hline Staph. epidermidis & 8 & 20 \\
Fungus & 4 & 10 \\
Others & 19 & 47.5 \\
No organism & $\frac{9}{40}$ & $\frac{22.5}{100.0}$ \\
Total & $\frac{40}{2}$ \\
\hline
\end{tabular}

XII. The early mortality was $10 \%$ (4 patients). One patient died at 45 days with uncontrolled infection complicated by brain abscesses despite valve replacement. Recurrence of infective endocarditis occurred in 1 patient 11 years after reoperation and required a second reoperation. Late infective endocarditis was seen in 2 patients at 12 months and 4 years, respectively, after reoperation. Neither had a history of infective endocarditis. The latter patient was successfully treated with antiobiotic therapy, but the former died of septic embolization. The actuarial freedom from infective endocarditis was $88 \%$ at 15 years (SE $\pm 8.6 \%$ ) (Fig. 6). No difference in the prevalence of postoperative infective endocarditis was found between patients with or without infective endocarditis $(p=$ 0.201 ).

\section{Discussion}

This study demonstrates that the use of unstented homograft valves in the setting of aortic valve reoperation offers good early and long-term results. The early mortality in the current era is low and similar to that of firsttime operations. ${ }^{8}$ Various authors reported a high early mortality of $15 \%$ to $40 \%^{9 \cdot 11}$ in the late 1970 s and early 1980 s, although this poorer result may relate to differences in indications for reoperation in an earlier era and less advanced perioperative care. Our current findings show improved survival in patients who had their reoperation more recently.

The demand for aortic valve reoperation is higher in recent years because patients with bioprosthetic and homograft valves inserted 10 to 20 years ago are having symptoms stemming from valve degeneration. In addi- 


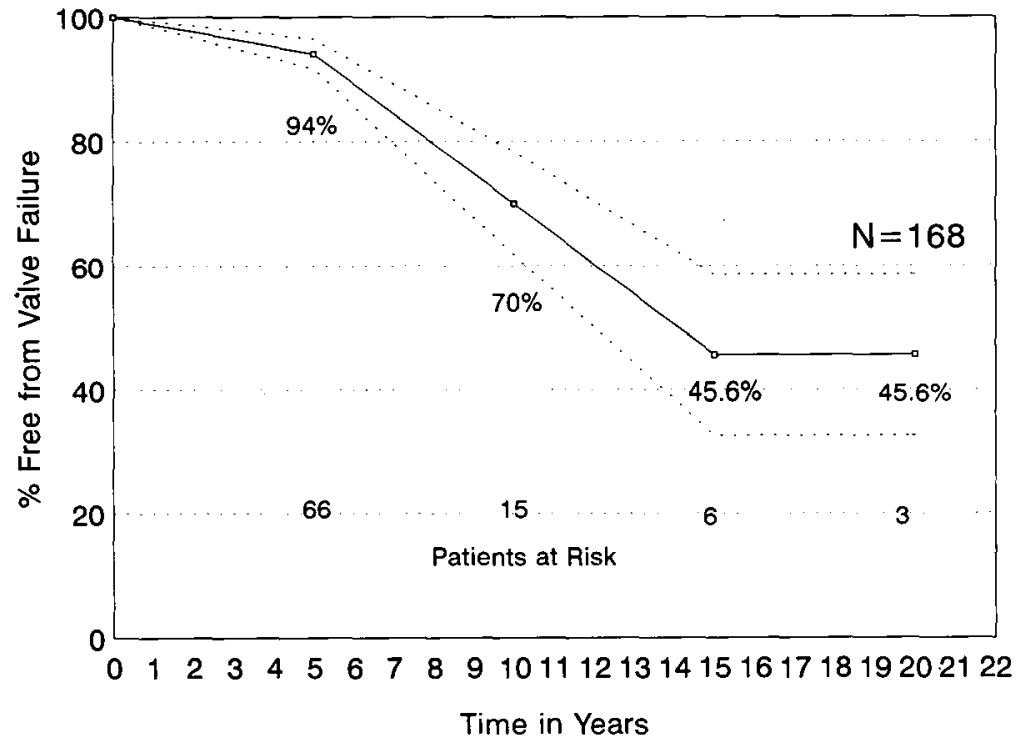

Fig. 6. Kaplan-Meier estimate of probability of freedom from valve-related death and reoperations. Early mortality is excluded.

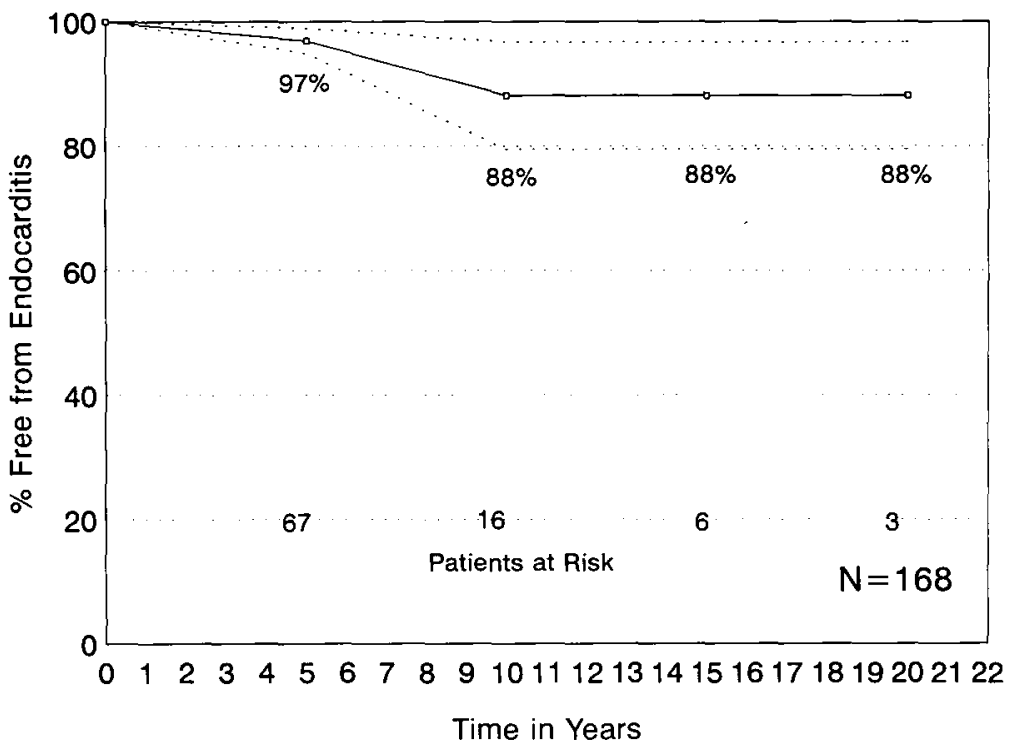

Fig. 7. Kaplan-Meier estimate of probability of freedom from postoperative infective endocarditis. Early (30-day) mortality is excluded.

tion, patients with mechanical prostheses are requiring treatment for thromboembolic phenomena, anticoagulant-related morbidity, and, rarely, mechanical failure. The benefits of early reoperation in symptom-free patients are evident in this study as well as in others. ${ }^{12,13}$

Concern has been expressed about late survival after reoperation..$^{12}$ The literature contains few reports on this issue. ${ }^{9,10,12,13}$ Our data show that reoperation in patients having homografts offers a similar 5-year survival to the reported series on first-time homograft ${ }^{14}$ and prosthetic valves insertions. ${ }^{15}$ This effect is particularly evident in patients who had a homograft replacement at the first operation as compared with those who received a prosthetic valve; the effect may relate to the characteristics of the valve substitute. Multivariate analysis did not reveal any patient-related factors to explain this difference. 
Prosthetic valves may produce a less than optimal flow pattern in the aortic root, which could affect systolic coronary blood flow and possibly cause repeated coronary microembolization. ${ }^{16}$ In contrast, homografts preserve the normal flow pattern, an effect which may influence long-term survival.

The freedom from homograft valve-related death and reoperation at 10 years has been reported to be between $30 \%$ and $90 \%$ for first-time aortic valve replacement. ${ }^{17-19}$ Our corresponding figure is $70 \%$ for aortic valve reoperation. Several factors have been implicated in homograft deterioration, including the preservation technique. ${ }^{17-19}$ Our experience lies predominantly with fresh and antibiotic-preserved homografts. Fresh homografts have only been available to us since 1980, which marked the beginning of our transplantation program, and our data show improved long-term results as compared with the antibiotic-preserved homografts. Viability of the homograft endothelium at the time of implantation may contribute to improved long-term valve performance. ${ }^{20}$ Previous concerns ${ }^{21}$ over the immunogenicity of fresh homografts leading to early degeneration are not supported by our data.

The reoperation interval was found to influence the long-term performance of the homografts, particularly among patients with a previous homograft replacement. The significance of this effect is unclear and may relate to immunologic or other factors. Certainly, in patients who had previous homografts there were no early failures that might have then suggested accelerated degeneration owing to sensitization to previous allografts. ${ }^{22}$

Several studies report that paraprosthetic leak is more prevalent after aortic valve reoperation than after the initial procedure. ${ }^{12,13}$ We did not have any cases of paravalvular leak even in the setting of infective endocarditis. This favorable result may relate to conformational adaptation of the homograft and the preferential use of aortic root replacement to match the size and shape of the native root, compensate for its distortion, and facilitate exteriorization of root abscesses. Many authors advocate the use of homografts in patients with infective endocarditis, especially prosthetic valve endocarditis. ${ }^{23-25}$ Our results support such use even in cases of uncontrolled infection, wherein we found no increase in early mortality or recurrent infection. Moreover, postoperative (early and late) infective endocarditis was not prevalent and was not related to the presence of preoperative infective endocarditis.

Despite an active transplantation program and access to two homograft banks, we find limited homograft availability to be a persistent problem as reflected by a figure of approximately $60 \%$ homograft valve replacements for the first and second operations (Fig. 1). Our unit policy is to offer homograft valve replacement as a first choice unless one is not available or the patient refuses to accept one.

In conclusion, homograft valves offer good early and long-term results in aortic valve reoperations, and the early mortality in the present era is similar to that of first-time operations. Reoperations for "failed" homografts give better early and long-term results than for "failed" prosthetic valves. Fresh homograft valves give better results than antibiotic-sterilized valves. In patients with prosthetic valve endocarditis, unstented homograft valves are the valve substitutes of choice.

We thank Dr. Robinson, of the School of Mathematical and Physical Sciences at the University of Sussex, Brighton, Sussex, for the statistical analysis of the data and Eileen Boyland for her contribution in the collection and analysis of the data.

\section{REFEREN CES}

1. Ross DN, Yacoub MH. Homograft replacement of the aortic valve. Prog Cardiovase Dis 1969;11:275-93.

2. Yacoub MH. Allograft aortic root replacement. In: Yankah AC, Hetzer R, Miller DC, Ross DN, Somerville J, Yacoub MH, eds. Cardiac valve allografts 1962-1987. New York: Springer-Verlag, 1988:149.

3. Edmunds LH Jr, Clark RE, Cohn LH, Miller G. Guidelines for reporting morbidity and mortality after cardiac valve operations. Ann Thorac Surg 1988;46:257-9.

4. Kaplan EL, Meier P. Nonparametric estimation from incomplete observation. J Am Stat Assoc 1958;53:457-81.

5. Dixon WJ. BMDP statistical software manual. Berkeley, Calif: University of California Press, 1990.

6. Cox DR, Oakes D. Multivariate analysis. In: Cox DR, Oakes D, eds. Analysis of survival data. London: Chapman and Hall, 1984:64.

7. Krzanowski WJ. Calculation of standard errors. In: Krzanowski WJ, ed. Principles of multivariate analysis. Oxford: Oxford University Press, 1988:123.

8. Kirklin JW, Barratt-Boyes BG. Aortic valve disease. In: Kirklin JW, Barratt-Boyes BG, eds. Cardiac surgery. 2nd ed. New York: Churchill Livingstone, 1992:491-571.

9. Sandza JG, Clark RE, Ferguson TB, Connors JP, Weldon CS. Replacement of prosthetic heart valves: a 15-year experience. J THORAC CARDIOVASC SURG 1977;74:864-74.

10. Syracuse DC, Bowman FO Jr, Malm JR. Prosthetic valve reoperations: factors influencing early and late survival. $\mathrm{J}$ Thorac Cardiovasc Surg 1979;77:346-52.

11. Cohn LH, Koster JK Jr, VandeVanter S, Collins JJ Jr. The in-hospital risk of rereplacement of dysfunctional mitral and aortic valves. Circulation 1982;66(Suppl):I153-6.

12. Blackstone EH, Kirklin JW. Death and other time related events after valve replacement. Circulation 1985;72:75367.

13. Husebye DJ, Pluth JR, Piehler JM, et al. Reoperation on prosthetic heart valves: an analysis of risk factors in 552 patients. J Thorac Cardiovasc Surg 1983;86:543-52.

14. McGiffin DC, O'Brien MF, Stafford EG, Gardner MA, 
Pohner PG. Long-term results of viable cryopreserved allografts aortic valves: continuing evidence for superior valve durability. J Cardiac Surg 1988;3(Suppl):289-96.

15. Alvarez L, Escudero C, Figuera D, Castillo-Olivares JL. The Björk-Shiley valve prosthesis: analysis of long-term evolution. J Thorac Cardiovasc Surg 1992;104:124958.

16. Bellhouse BJ, Bellhouse FH, Reid KG. Fluid mechanics of the aortic root with application to coronary flow. Nature 1968;219:1059-61.

17. Khaghani A, Dhalla N, Penta A, et al. Patient status ten years or more after aortic valve replacement using antibiotic sterilized homograft. In: Bodnar E, Yacoub M, eds. Biologic and bioprosthetic valves. New York: Yorke Medical Books, 1986:38.

18. O'Brien MF, Stafford G, Gardner M, et al. The viable cryopreserved allograft aortic valve. J Cardiac Surg 1987;2 (Suppl 1):153-9.

19. Daly RD, Orszulak TA, Schaff HV, McGovern E, Wallace RB. Long-term results of aortic valve replacement with non-viable homografts. Circulation 1991;84(Suppl): III81-8.

20. Thompson R, Yacoub MH, Ahmed M, Somerville W, Towers M. The use of "fresh" unstented homograft valves for replacement of the aortic valve: analysis of 8 years' experience. J THORAC Cardiovasc SuRG 1980;79:896903.

21. Yacoub MH. Applications and limitations of histocompatibility in clinical cardiac valve allograft surgery. In: Yankah AC, Hetzer R, Miller DC, Ross DN, Somerville J, Yacoub $\mathrm{MH}$, eds. Cardiac valve allografts 1962-1987. New York: Springer-Verlag, 1988:95.

22. Yankah AC, Wottge HU, Muller-Ruchholtz W. Prognostic importance of viability and a study of a second set allograft valve: an experimental study. J Cardiac Surg 1988;3:263-70.
23. Glazier JJ, Verwilghen J, Donaldson RM, Ross DN Treatment of complicated prosthetic aortic valve endocarditis with annular abscess formation by homograft aortic root replacement. J Am Coll Cardiol 1991;17:1177-82.

24. Haydock D, Barratt-Boyes B, Macedo T, Kirklin JW, Blackstone EH. Aortic valve replacement for infective endocarditis in 108 patients. J THORAC CARDIOvaSC SURG 1992;103:103-9.

25. McGiffin DC, Galbraith AJ, McLachlan GJ, et al. Aortic valve infection. J THORAC CARDIOVASC SuRG 1992;104: 511-20.

\section{Discussion}

Dr. Charles Yankah (Berlin, Germany). I congratulate Dr. Albertucci and his colleagues for their study of the use of a second homograft in reoperations. Their results seem to support the evidence that a second homograft at a reoperation does not actually infiuence the long-term valve function; that is, early degeneration in not observed clinically, whereas in animal experiments a "second set reaction" is more often observed with accelerated rejection and consequently with early degeneration. At this juncture the question of viability should be raised. Dr. Albertucci, which of the standard techniques did you use in your reoperations? Did you use mostly aortic root replacement or subcoronary valve replacement? These two techniques might also influence the long-term performance of the valves. Second, on what basis do you use a homograft instead of other valve devices at reoperations?

Dr. Albertucci. We used a homograft as a freehand graft in about two thirds of the patients and as a root in about one third of the patients. Multivariate analysis did not demonstrate any difference in long-term outcome with regard to valve deterioration between freehand insertion or root insertion.

Because our unit is biased toward homografts, we will use a homograft whenever one is available unless the patient refuses to have another homograft. The homograft has been our valve of choice. 